\title{
Correction to: Health-Care and Societal Costs Associated with Non-Persistence with Subcutaneous TNF- $\alpha$ Inhibitors in the Treatment of Inflammatory Arthritis (IA): A Retrospective Observational Study
}

Johan Dalén · Anushri Chitkara · Axel Svedbom • Tor Olofsson •

Amy Puenpatom · Christopher M. Black · Zaina P. Qureshi (D)

( $)$ Springer Healthcare Ltd., part of Springer Nature 2022

Correction to: Adv Ther

https://doi.org/10.1007/s12325-021-01970-w

A retrospective graphical abstract has been added to this article post-publication. The original article has also been updated.

\section{Graphical Abstract}

The original article can be found online at https://doi. org/10.1007/s12325-021-01970-w.

J. Dalén · A. Svedbom

ICON Plc, Stockholm, Sweden

A. Chitkara

ICON Plc, Bangalore, India

T. Olofsson

Department of Clinical Sciences Lund,

Rheumatology, Lund University, Skåne University

Hospital, Lund, Sweden

A. Puenpatom · C. M. Black · Z. P. Qureshi ( $₫)$ Center for Observational and Real-World Evidence (CORE), Merck \& Co., Inc., 2000 Galloping Hill Rd, Kenilworth, NJ 07331, USA

e-mail: zaina.qureshi@merck.com 
HEALTH-CARE AND SOCIETAL COSTS ASSOCIATED WITH NON-PERSISTENCE WITH SUBCUTANEOUS (SC) TNF- $\alpha$ INHIBITORS FOR INFLAMMATORY ARTHRITIS (IA)

Johan Dalén, Anushri Chitkara, Axel Svedbom, Tor Olofsson, Amy Puenpatom, Christopher M. Black, Zaina P. Qureshi

A RETROSPECTIVE, OBSERVATIONAL STUDY USING SWEDISH HEALTH DATA REGISTERS

\section{PATIENTS:

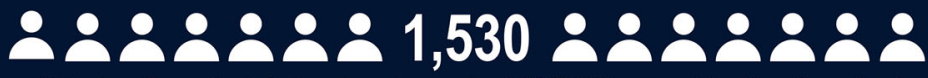

Biologic-naive patients in Sweden who received SC-TNFi treatment for IA and remained eligible after applying the inclusion criteria.

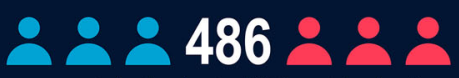

A propensity score matched cohort of 486 matched pairs was generated as persistent and non-persistent patients.

Persistence: Time from treatment initiation to treatment discontinuation or switch to another SC-TNFi or bDMARD

TOTAL DIRECT AND

INDIRECT COSTS

PRE-INDEX DATE

\section{$\$ 16,600$}

$[95 \% \mathrm{Cl}, 14,331-18,696]$

\section{Total direct and indirect costs were significantly higher among non-persistent patients 12 months pre-index date}

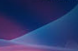

Among biologic-naive patients in Sweden treated with SC-TNFi for IA, persistent patients incurred $\sim 40 \%$ lower aggregated direct and indirect costs than non-persistent patients 12 months post-index date.

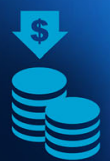

TOTAL DIRECT AND INDIRECT COSTS POST-INDEX DATE*

\section{$\$ 13,465$}

[95\% $\mathrm{Cl}, 11,415-15,729]$
Persistent patients significantly decreased total direct and indirect costs 12 months post-index date.
TOTAL DIRECT AND

INDIRECT COSTS

PRE-INDEX DATE

$\$ 20,802$

$[95 \% \mathrm{Cl}, 18,335-23,429]$

*Please refer to the journal article for a full analysis of persistent and non-persistent cohort data.

bDMARD = biological disease-modifying antirheumatic drug; IA = inflammatory arthritis; SC-TNFi = subcutaneous tumor necrosis factor inhibitor.

TOTAL DIRECT AND INDIRECT COSTS POST-INDEX DATE*

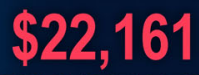

[95\% Cl, 19,754-24,556] 